Central Washington University

ScholarWorks@CWU

All Faculty Scholarship for the College of the Sciences

$9-1-2001$

Present Day Kinematics of the Eastern California Shear Zone from a Geodetically Constrained Block Model
S. C. McClusky
S. C. Bjornstad
B. H. Hager
R. W. King
B. J. Meade

See next page for additional authors

Follow this and additional works at: https://digitalcommons.cwu.edu/cotsfac

Part of the Geomorphology Commons, Geophysics and Seismology Commons, and the Tectonics and Structure Commons 


\section{Authors}

S. C. McClusky, S. C. Bjornstad, B. H. Hager, R. W. King, B. J. Meade, M. Meghan Miller, F. C. Monastero, and B. J. Souter 


\title{
Present Day Kinematics of the Eastern California Shear Zone from a Geodetically Constrained Block Model
}

\author{
S. C. McClusky ${ }^{1}$, S. C. Bjornstad ${ }^{2}$, B. H. Hager ${ }^{1}$, R. W. King ${ }^{1}$, B. J. Meade ${ }^{1}$, \\ M. M. Miller ${ }^{3}$, F. C. Monastero ${ }^{2}$, and B. J. Souter ${ }^{4}$
}

\begin{abstract}
We use Global Positioning System (GPS) data from 1993-2000 to determine horizontal velocities of 65 stations in eastern California and western Nevada between $35^{\circ}$ and $37^{\circ} \mathrm{N}$. We relate the geodetic velocities to fault slip rates using a block model that enforces path integral constraints over geologic and geodetic time scales and that includes the effects of elastic strain accumulation on faults locked to a depth of $15 \mathrm{~km}$. The velocity of the Sierra Nevada block with respect to Nevada is $11.1 \pm 0.3 \mathrm{~mm} / \mathrm{yr}$, with slip partitioned across the Death Valley, $(2.8 \pm 0.5 \mathrm{~mm} / \mathrm{yr})$, Panamint Valley $(2.5 \pm 0.8 \mathrm{~mm} / \mathrm{yr})$, and Airport Lake/Owens Valley $(5.3 \pm 0.7 / 4.6 \pm 0.5 \mathrm{~mm} / \mathrm{yr})$ faults. The western Mojave block rotates at $2.1 \pm 0.8^{\circ} / \mathrm{My}$ clockwise, with $3.7 \pm$ $0.7 \mathrm{~mm} / \mathrm{yr}$ of left lateral motion across the western Garlock Fault. We infer $11 \pm 2 \mathrm{~mm} / \mathrm{yr}$ of right lateral motion across the Mojave region of the Eastern California Shear Zone.
\end{abstract}

\section{Introduction}

About $25 \%$ of the relative motion between the Pacific and North American plates occurs east of the San Andreas fault zone (SAFZ) within a complex region characterized geologically [Dokka and Travis, 1990] and geodetically [Sovage et al., 1990] as the Eastern California shear zone (ECSZ). South of the Garlock fault, shear within the eastern Mojave Desert occurs on right lateral faults that are nearly parallel to the direction of plate motion [Sauber et al., 1994, Miller et al., 2001]. North of the Garlock fault, in the southern Walker Lane belt, a series of faults accommodates both right lateral and normal motion. We present surface velocities estimated from GPS measurements of this region and relate these geodetic velocities to geologic fault slip rates using a block model.

\section{GPS Measurements and Analysis}

The principal data used for this study were acquired in 14 surveys conducted from 1993-2000 by the National Imaging and Mapping Agency (NIMA) under the auspices of the Navy

\footnotetext{
${ }^{1}$ Department of Earth, Atmospheric, and Planetary Sciences, MIT, Cambridge, MA.

${ }^{2}$ Geothermal Program Office, Naval Air Weapons Station, China Lake, $\mathrm{CA}$.

${ }^{3}$ Department of Geological Sciences, Central Washington University, Ellensburg, WA.

${ }^{4}$ Souter Computing Services, Baltimore, MD, 21239.
}

Copyright 2001 by the American Geophysical Union.

Paper number 2001GL013091.

0094-8276/01/2001GL013091\$05.00
Geothermal Program Office (GPO) and focused on the Coso region east of the Sierra Nevada Front. Each survey consisted of three to twelve 6-hour occupations of 23-34 monuments. Additional data come from annual surveys, 1993-1996 covering the broader Eastern California Shear Zone (ECSZ) region over the same time interval by Central Washington University (CWU) and the University of Miami (UM), [Miller et al., 2001; Dixon et al., 2000]. We also incorporated data from annual surveys, 1993-1996, in the Hunter Mountain, Panamint Valley and Death Valley regions by the Nuclear Regulatory Commission (NRC), California Institute of Technology, and the Harvard-Smithsonian Center for Astrophysics [Bennett et al., 1997] and along a transect measured by the United States Geological Survey (USGS) [Gan et al., 2000] in 1994, 1996, 1997, and 1999.

We analyze the data using the GAMIT/GLOBK software [King and Bock, 1999; Herring, 1999] in a two-step approach (e.g., Dong et al. [1998]). In the first step, we use GPS phase observations from each day to estimate station coordinates, the zenith delay of the atmosphere at each station, and orbital and Earth orientation parameters (EOP). In the second step we use the loosely constrained estimates of station coordinates, orbits, and EOP and their covariances from each day, aggregated by survey, as quasi-observations to estimate a consistent set of coordinates and velocities. For the analysis of all but the GPO data, we provide orbital control and tie the regional measurements to an external reference frame by including in the regional analysis data from 3-4 continuously operating stations of the International GPS Service (IGS) and by combining the regional quasi-observations with quasiobservations from an analysis of phase data from over 100 IGS stations performed by the Scripps Orbital and Permanent Array Center (SOPAC) at UC San Diego [Bock et al. 1997]. For the GPO surveys we do not mix the phase observations from the regional and IGS stations in order to avoid errors due to mismatched receivers and antennas. The most serious of these errors is an unknown but apparently constant offset in the sampling time of the codeless Ashtech LM-XII receivers used prior to November, 1996. This offset leads to position errors of $20-50 \mathrm{~mm}$ if the LM-XII data are differenced with those from other receivers, but has no significant effect on our estimates of relative positions within the GPO network. For our daily analysis of the GPO surveys we use IGS orbits constrained to one part in $10^{8}$. The GPO network is tied to an external reference frame in the second step of our analysis through 10 stations in common with the CWU/UM, NRC and/or USGS networks.

Before estimating velocities in the second step of our analysis, we examine the time series of position estimates to determine the appropriate weights to be applied to each group's surveys. For the velocity solution, we reweight the quasi-observations such that the normalized long-term scatter 


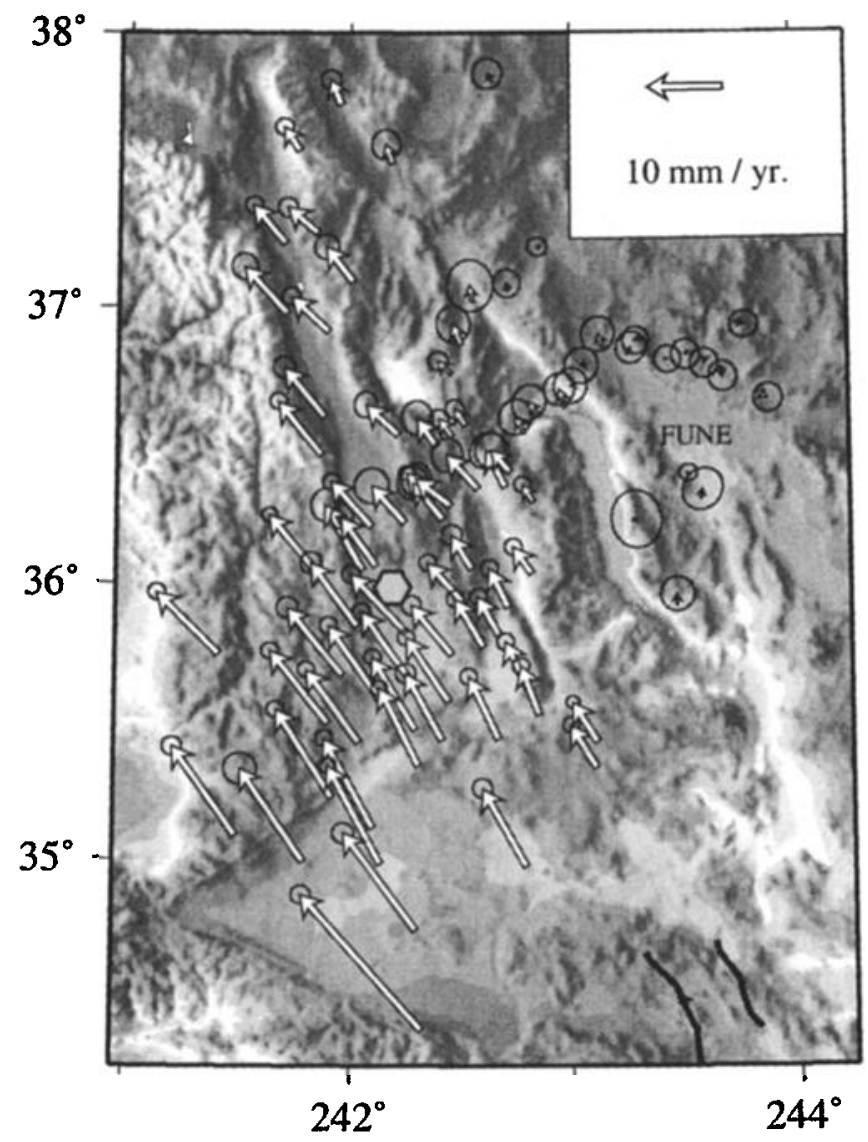

Figure 1. Horizontal velocity field for the ECSZ. Velocities are rotated into a North American reference frame and then shown relative to station FUNE. Heavy lines in the southeast (from west to east) show the locations of the 1992 Landers and 1999 Hector Mine Earthquake surface ruptures. The hexagonal symbol indicates the location of the Coso geothermal area.

in horizontal position for each group is unity. Finally, to account for correlated errors, we add to the assumed error in horizontal position a random walk component of $0.5 \mathrm{~mm} / V_{\mathrm{yr}}$.

\section{Kinematic Model}

To relate the geodetically determined velocities ${ }^{5}$ (Figure 1) to geologic slip rates on faults, we must account for elastic strain accumulation. The classic model of a single, infinitely long fault [e.g., Savage and Burford, 1973] assumes that an elastic half-space is strained by slip imposed at the geologic rate on the down-dip extension of the fault below the locking depth, $D$. The geodetic velocity can be calculated as the difference between the geologic motions of the blocks and that caused by an equal slip deficit rate imposed on the fault above $D$. More realistic models incorporate a viscoelastic rheology characterized by a relaxation time, $\tau$, loaded by earthquakes with repeat time, $T$. Models of an elastic layer of thickness $D$ and modulus $\mu$ overlying a viscoelastic halfspace of viscosity $\eta$, with $\tau=\eta / \mu$, show little variation in interseismic velocities if $\tau / T>0.5$ [e.g., Savage and Lisowski, 1998], with the velocities closely approximating those of the classic model. If $\tau / T<0.2$, significant variations arise that depend on $\tau / T$ and the time, $t$, since the last earthquake. Near

\footnotetext{
${ }^{3}$ Available via anonymous ftp from ftp:/kosmos.agu.org, directory "append" (Username "anonymous," Password "guest"); subdirectories are arranged by paper number.
}

the fault, early in the earthquake cycle, the geodetic rates are higher than the geologic rate, while late in the cycle, the apparent locking depth is much greater than $D$. In the farfield, the velocities approach the geologic rate.

We extend the Savage and Burford (1973) model to include the effects of multiple intersecting faults of finite length and varying orientations. As in their classic model, we assume that there is negligible variation with time of the interseismic velocity field. We use a block model [Souter, 1998, see Meade et al., 2001, for details] that requires that geologic surface displacements are the sum of coseismic and interseismic displacement fields, enforcing the same path integral constraint over both geodetic and geologic time scales. That is, the relative velocity between any two points does not depend on the path connecting them. Block boundaries are defined by faults with slip rate components determined in an internally consistent manner by the projection of the relative block velocity vector onto the fault plane. The surface deformation associated with backslip on these faults is modeled using dislocation theory [Okada, 1985], assuming a Poisson half-space. In general, the surface traces of the block boundaries are coarse representations of faults with Quaternary displacements [Jennings, 1994]. Individual slip rate estimates may reflect the total slip budget of several faults that are closely spaced. In our model all faults east of the SAF are vertical. Souter [1998] showed that the horizontal surface displacements calculated using faultperpendicular displacements on a vertical dislocation are nearly the same as those calculated using a more realistic geometry with dip-slip displacements on dipping dislocations.

A velocity of $\sim 2 \mathrm{~mm} / \mathrm{yr}$ associated with the SAFZ extends into the ECSZ region. We incorporate this effect by including surface velocity estimates from a model of California, west of the SAF [Souter, 1998; B. J. Meade, unpublished results], where block motions are estimated using the Southern California Earthquake Center (SCEC) horizontal deformation velocity map [Shen, 1997].

We estimate block motions using a weighted least squares inversion of the velocity vectors, with the data weighted by

Table 1.

\begin{tabular}{cccc}
\hline Fault name & $\begin{array}{c}\text { Fault } \\
\text { symbol }\end{array}$ & $\begin{array}{c}\text { Strike slip } \\
\text { rate }^{\mathbf{a}} \\
(\mathrm{mm} / \mathrm{yr})\end{array}$ & $\begin{array}{c}\text { Fault normal } \\
\text { rate }^{\mathrm{b}} \\
(\mathrm{mm} / \mathrm{yr})\end{array}$ \\
\hline Garlock & G1 & $3.2 \pm 0.7$ & $5.8 \pm 0.7$ \\
Garlock & G2 & $4.0 \pm 0.7$ & $3.1 \pm 0.7$ \\
Garlock & G3 & $3.5 \pm 0.6$ & $1.6 \pm 0.6$ \\
Garlock & G4 & $1.1 \pm 1.3$ & $4.0 \pm 1.2$ \\
Owens Valley & OV1 & $-5.0 \pm 0.6$ & $-1.9 \pm 0.7$ \\
Owens Valley & OV2 & $-4.6 \pm 0.5$ & $-2.7 \pm 0.6$ \\
Airport Lake & AL & $-5.3 \pm 0.7$ & $-0.3 \pm 0.7$ \\
Panamint Valley & PV & $-2.5 \pm 0.8$ & $-1.9 \pm 1.0$ \\
Hunter Mountain & HM & $-3.2 \pm 1.0$ & $0.1 \pm 0.9$ \\
Saline Valley & SV & $-2.7 \pm 0.9$ & $-1.7 \pm 1.0$ \\
Eureka Valley & EV & $-1.1 \pm 0.8$ & $-3.0 \pm 0.9$ \\
Furnace Creek & FC & $-2.7 \pm 0.6$ & $0.8 \pm 0.6$ \\
Fish Lake & FL & $-5.8 \pm 0.4$ & $-0.4 \pm 0.4$ \\
Death Valley & DV & $-2.8 \pm 0.5$ & $-0.7 \pm 0.6$ \\
Avawatz Mountains & AM & $-2.8 \pm 0.5$ & $0.5 \pm 0.6$ \\
Calico-Blackwater & CB1 & $-1.7 \pm 1.5$ & $-0.3 \pm 1.5$ \\
Calico-Blackwater & CB2 & $-1.4 \pm 1.4$ & $-4.1 \pm 1.5$ \\
Goldstone Lake & GL & $-6.4 \pm 1.7$ & $1.3 \pm 1.7$ \\
Eastern Mojave & EM1 & $-2.8 \pm 0.5$ & $-0.6 \pm 0.6$ \\
Eastern Mojave & EM2 & $-6.5 \pm 1.6$ & $0.8 \pm 1.7$ \\
\hline & & & \\
\hline & & & \\
\hline
\end{tabular}

: negative values indicate right lateral motion

b : negative values indicate opening 


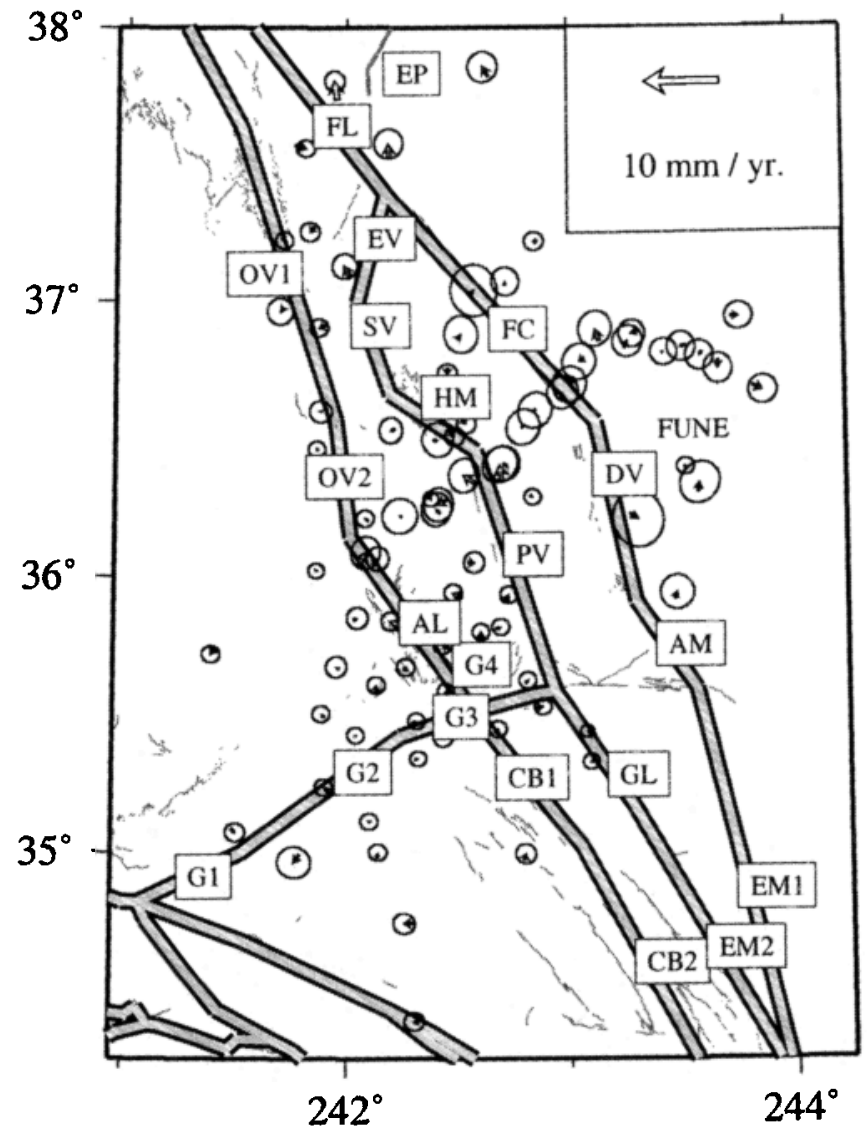

Figure 2. Residual velocity field with $95 \%$ confidence ellipses. Labels are abbreviations for fault names. Slip rate estimates for each fault are given in Table 1 .

the reciprocal of the squares of their error estimates. The reference frame of the solution is realized by requiring that the weighted mean of the residual velocities of the 17 sites on the eastern most block south of $37.4^{\circ} \mathrm{N}$ is zero. In general, horizontal motions of a block are described by three parameters: two velocity components and a rotation rate. Faults bounding a rotating block have slip rates that vary along strike. The elastic deformation associated with these faults is calculated by dividing them into short segments (one $\mathrm{km}$ or less) and using locally determined slip rates. An inversion carried out with translations only, in order to decrease the number of degrees of freedom, showed apparent unmodeled rotation of the western Mojave block. For the model presented here, only that block is permitted to rotate, with an inferred rate of $2.1 \pm 0.8^{\circ} \mathrm{My}$ clockwise. Fault slip rate estimates are given in Table 1. The residual (observed predicted) velocity field is shown in Figure 2.

\section{Discussion}

The $\chi^{2}$ per degree of freedom (dof) is 0.8 , with a mean residual magnitude of $0.6 \mathrm{~mm} / \mathrm{yr}$ for each velocity component. It appears that the data and the model are consistent and that we have used an appropriate number of free parameters.

Because unmodeled effects such as variations in elastic moduli can have effects on velocity gradients comparable to those of varying $D$ (e.g., Hager et al., 1999), we choose not to fine-tune the locking depths of individual fault segments; rather we find an optimal regional locking depth, $D=15 \mathrm{~km}$, and investigate the effects of varying it. The main effect of a larger $D$ is to put $\sim 1 \mathrm{~mm} / \mathrm{yr}$ more slip on the faults bounding the Sierra Nevada, while a smaller $D$ yields less slip on these faults. Variations of slip rates with $D=5$ to $25 \mathrm{~km}$ are at about the $1-\sigma$ level about the slip rate estimates with $D=15$ $\mathrm{km}$.

Our slip rate estimates for strike-slip motions on the faults north of the Garlock indicate that almost half of the ECSZ shear is concentrated on the Airport Lake/Owens Valley faults $(5.3 \pm 0.7,5.0 \pm 0.6$, and $4.6 \pm 0.5 \mathrm{~mm} / \mathrm{yr}$ on $\mathrm{AL}, \mathrm{OV} 1$, and OV2), with $2.5 \pm 0.8 \mathrm{~mm} / \mathrm{yr}$ on the Panamint Valley fault and $2.8 \pm 0.5 \mathrm{~mm} / \mathrm{yr}$ on the Death Valley fault. Bennett et al. [1997] gave a comparable total for Death Valley plus Panamint Valley, but had insufficient data to resolve either their individual contributions or the rate of slip on the Owens Valley fault. Our rates are consistent, within the errors, with those of Gan et al. [2000], although they inferred a somewhat higher rate, $6.9 \pm 1.6 \mathrm{~mm} / \mathrm{yr}$, for the Owens Valley fault, probably because they ignored the shear associated with the SAF. Dixon et al. [2000] used a simple 2-D viscoelastic model to infer $3 \pm 2 \mathrm{~mm} / \mathrm{yr}$ motion on OV1, also indistinguishable statistically. Beanland and Clark [1994] estimated a Holocene rate on the Owens Valley fault in the OV1OV2 region of $2 \pm 1 \mathrm{~mm} / \mathrm{yr}$ by assuming that the 3 most recent earthquakes there had the same average slip that they found for the 1872 event, $6 \mathrm{~m}$. If not all the displacement on basement faults penetrates through the thick sediment cover to the surface, the $10 \mathrm{~m}$ maximum surface displacement might provide a better estimate of basement offset, implying a rate of $3 \pm 2 \mathrm{~mm} / \mathrm{yr}$, consistent with the geodetic rate.

We estimate $5.8 \pm 0.4 \mathrm{~mm} / \mathrm{yr}$ slip on the Fish Lake Valley (FL) fault zone, consistent with the $8 \pm 2 \mathrm{~mm} / \mathrm{yr}$ of Dixon et al. [2000]. The Quaternary rate on the FL segment is 6-12 $\mathrm{mm} / \mathrm{yr}$, with evidence for deceleration to $1-3 \mathrm{~mm} / \mathrm{yr}$ over the past 50-75 ka, with slip transferred to faults to the east via the Emigrant Peak (EP) fault zone [Reheis and Sawyer, 1997]. The three sites northeast of FL exhibit coherent residual velocities. Because we have only one site to the NW of EP, we do not invert for the motion of a separate block, but the residual velocities of the sites north of FL suggest $\sim 3 \mathrm{~mm} / \mathrm{yr}$ of slip is transferred to $\mathrm{EP}$, which would reduce the slip on FL.

We also estimate the fault-perpendicular component of motion. The divergence between the blocks increases from east to west, from $0.7 \pm 0.6 \mathrm{~mm} / \mathrm{yr}$ on block boundary DV to $1.9 \pm 1.0 \mathrm{~mm} / \mathrm{yr}$ on $\mathrm{PV}$, to $2.7 \pm 0.6 \mathrm{~mm} / \mathrm{yr}$ on OV2 Divergence should promote volcanism and geothermal activity. The rapid divergence on OV1 and OV2 may help to explain the high rate of volcanic activity in the Owens Valley region and geothermal activity to the south.

The conclusion that the Owens Valley/Airport Lake faults have higher rates of slip than the Death Valley fault differs substantially from that of Hearn and Humphreys [1998], who inferred just the opposite. However, they had only the velocity of a single VLBI site, Mojave, to constrain the distribution of slip in this region.

South of the Garlock fault, the locations of boundaries $\mathrm{CB} 2, \mathrm{EM} 1$, and EM2 are poorly constrained, although the surface faulting, focal mechanisms, and aftershock distributions of the Landers and Hector Mine earthquakes suggest the appropriateness of our choice of boundaries. To avoid transient velocities associated with the Landers earthquake, we do not include GPS data in this region. Our model predicts $\sim 11 \mathrm{~mm} / \mathrm{yr}$ of right lateral motion across the southern Mojave at latitude $34.5^{\circ}$, consistent with previous geodetic studies of the southern Mojave based on triangulation [Savage et al., 1990; Sauber et al., 1994], 
demonstratung the utility of the path integral constraint implicit in the block model. The total right lateral slip budget in the southern Mojave in our model is consistent with the preferred 6 - $10 \mathrm{Ma}$ geologic rate of $6-12 \mathrm{~mm} / \mathrm{yr}$ given by Dokka and Travis [1990].

West of its intersection with the Calico-Blackwater fault, the Garlock has $3.5 \pm 0.6 \mathrm{~mm} / \mathrm{yr}$ of slip. Miller et al. [2001], using fewer data and a dislocation model that does not include block rotation or satisfy path integral constraints, concluded that the slip rate on the western Garlock is only 1-2 mm/yr. Our estimate is consistent with the Holocene rate of $4-7$ $\mathrm{mm} / \mathrm{yr}$ [McGill and Sieh, 1991]. Both are less than the paleoseismologic estimate of $10-12 \mathrm{~mm} / \mathrm{yr}$, perhaps resulting from a cluster of earthquakes over the past $1.5 \mathrm{ka}[M c G i l l$ and Rockwell, 1998]. To the east of this intersection we estimate the left lateral strike slip rate on $\mathrm{G} 4$ to be $1.1 \pm 1.3 \mathrm{~mm} / \mathrm{yr}$, significantly less than the Holocene estimate of $4-9 \mathrm{~mm} / \mathrm{yr}$ [McGill and Sieh; 1993] The residual velocities of the 3 sites on the block to the south of G4 suggest that unmodeled rotation could explain this discrepancy.

Ron et al. [2001] proposed a model in which the western Mojave undergoes simple shear on faults parallel to the SAF, with negligible rotation. We tested this model by splitting the western Mojave block in two and allowing these two blocks to translate without rotating. Despite having one additional degree of freedom, this model has a $\chi^{2}$ for the 9 sites in the western Mojave $19 \%$ greater than the model with a single rotating western Mojave block In addition, the inferred slip rate of the western Garlock is $2 \pm 2 \mathrm{~mm} / \mathrm{yr}$, in worse agreement with the geologic rate. We cannot reject the Ron et al. model, although we prefer the rotating block model because it fits the data better with one less parameter.

Acknowledgments. We thank Bob Wideman, Larry Schneider, and the NIMA survey teams for nearly flawless GPS observations in the geothermal surveys. We are grateful to Brian Wernicke (Caltech), Tim Dixon (UM), and Will Prescott (USGS) for sharing their data, to Tim Dixon, Liz Hearn, and Jim Savage for discussions and comments on the manuscript, and to Rick Bennett for his review. This research was supported at MIT by the Navy Geothermal Program Office under contract N68936-95-C-0371, and by SCEC, and at CWU by NASA under the Dynamics of the Solid Earth Program SCEC is funded by NSF Cooperative agreement EAR8920136 and USGS cooperative agreements 14-08-0001-A0899 and 1434-HQ-97AG01718. The SCEC contribution number for this paper is 550 .

\section{References}

Beanland, S.. and M. M. Clark, The Owens Valley fault zone, eastern California, and surface faulting associated with the 1872 earthquake, U. S. Geol. Surv. Bull., 1982, 29p., 1994.

Bennett, R. A., B P. Wernicke, J. L. Davis, P. Elosegui, J. K. Snow, M. J. Abolins, M. A. Mouse, G. L. Stirewalt, and D. A. Ferrill, Global Positioning System constraints on fault slip rates in the Death Valley region, California and Nevada, Geophys. Res. Lett., 24, 3073-3076, 1997.

Bock, Y., J. Behr, P. Fang, J. Dean, and R. Leigh, Scripps Orbit and Permanent Array Center and Southern California Permanent GPS Geodetic Array, in The Global Positioning System for the Geosciences, Natl. Acad. Press, Washington, D. C, 55-61, 1997.

Dixon, T. H., M. M. Miller, F. Farina, H. Wang, and D. J. Johnson, Present-day motion of the Sierra Nevada block, and some implications for Basin and Range tectonics, Tectonics, 18, 1-24, 2000.

Dokka, R. K., and C. J. Travis, Role of the Eastern California Shear Zone in accommodating Pacific-North American plate motion, Geophys. Res. Lett., 17, 1323-1326, 1990.
Dong, D., T. A. Herring, and R. W. King, Estimating regional deformation from a combination of space and terrestrial geodetic data, J. Geod., 72, 200-214, 1998.

Gan, W., J. L. Svarc, J. C. Savage, and W. H. Prescott, Strain accumulation across the Eastern California shear zone at latitude $36^{\circ} 30^{\prime}$ N , J. Geophys. Res., 105, 16,229-16,236.

Hager, B. H., G. A. Lyzenga, A. Donnellan, and D. Dong, Reconciling rapid strain accumulation with deep seismogenic fault planes in the Ventura basin, California, J. Geophys. Res., 104, 25,207$25,219,1999$.

Hearn, E. H., and E. D. Humphreys, Kinematics of the southern Walker lane belt and motion of the Sierra Nevada block, California, J. Geophys. Res , 103, 27,033-27,049, 1998.

Herring, T. A., GLOBK: Global Kalman Filter VLBI and GPS analysis Program V5.0, internal memorandum, MIT, Cambridge, 1999.

Jennings, C. W., Fault activity map of California and adjacent areas with locations and ages of recent volcanc eruptions, California Division of Mines and Geology, Dept of Conservation, Sacramento, CA, 1994.

King, R. W., and Y. Bock, The GAMIT GPS Analysis Software V9.8, internal memorandum, MIT, Cambridge, 1999.

McGill, S., and K. Sieh, Surficial offsets on the central and eastern Garlock Fault associated with prehistoric earthquakes, J. Geophys. Res , 96, 121,597-21,621, 1991.

McGill, S., and K. Sieh, Holocene slip rate of the central Garlock Fault in southeastern Searles Valley, California, J. Geophys. Res., 98, 14,217-14,231, 1993.

McGill, S., and T. Rockwell, Ages of late Holocene earthquakes on the central Garlock Fault near El Paso Peaks, California, J.Geophys. Res., 103, 7265-7279, 1998.

Meade, B. J , B. H. Hager, and R. E. Reilinger, Estimates of seismic potential in the Marmara region from block models of secular deformation constrained by GPS measurements, Bull. Seismo. Soc. Am., in press, 2001 .

Miller, M. M., D. J. Johnson, T. H. Dixon, and R. K. Dokka, Refined kinematics of the Eastern California shear zone from GPS observations, 1993-1998, J. Geophys. Res., 106, 2245-2263, 2001.

Okada, Y. Surface deformation to shear and tensile faults in a halfspace, Bull. Seismol. Soc. Am. 75, 1135-1154, 1985.

Reheis, M. C., and T. L Sawyer, Late Cenozoic history and slip rates of the Fish lake Valley, Emigrant Peak, and Deep Springs fault zones, Nevada and California, Bull Geol.. Soc. Am., 109, 280299, 1997.

Ron, H., G. Beroza, and A. Nur, Simple model explains complex faulting, EOS, Trans. Am. Geophys. Union, 82, 125-129, 2001.

Sauber, J., W. Thatcher, S. C. Solomon, and M. Lisowski, Geodetic slip rate for the Eastern California shear zone and the recurrence time of Mojave Desert earthquakes, Nature, 367, 264-266, 1994.

Savage, J. C., and R. O. Burford, Geodetic determination of relative plate motion in central California, J. Geophys. Res., 78, 832-845, 1973.

Savage, J. C., and M. Lisowski, Viscoelastic coupling model of the San Andreas fault along the Big Bend, southern California, $J$. Geophys. Res., 103,7281-7292, 1998.

Savage, J. C., M. Lisowski, and W. H. Prescott, An apparent shear zone trending north-northwest across the Mojave Desert into Owens Valley, eastern California, Geophys. Res. Lett., 17, 2113$2116,1990$.

Shen, Z., D. Dong, T. Herring, K. Hudnut, D. Jackson, R. King, S. McClusky, L. Sung, Crustal deformation in Southern California, EOS, Trans. Am. Geophys. Union, 78, 477-482, October 1997.

Souter, B. J., Comparisons of geologic models to GPS observations in southern California, Ph. D. thesis, MIT, Cambridge, 1998.

B. H. Hager, R. W. King, S. M. McClusky, B. J. Meade, Rm 54614, Department of EAPS, Massachusetts Institute of Technology, Cambridge, MA 02139. (e-mail simon@chandler.mit.edu)

S. Bjornstad, F. Monastero, Geothermal Program Office, Code 83G000D, NAWS, China Lake, CA 93555

M. M. Miller, Dept. of Geological Sciences, Central Washington University, Ellensburg, WA 98926

B. J. Souter, Souter Computing Services, Baltimore, MD, 21239.

(Received 02/27/2001; revised 05/10/2001, accepted 06/27/2001) 